\title{
Influence of chlorhexidine concentration on microtensile bond strength of contemporary adhesive systems
}

\section{Edson Alves de Campos ${ }^{(a)}$ Gisele Maria Correr(a) \\ Denise Piotto Leonardi ${ }^{(b)}$ \\ Eduardo Pizzatto(a) \\ Eduardo Caregnatto Morais ${ }^{(c)}$}

(a) Full Professor; (b) Assistant Professor; (c) Graduate Student - Master of Science Program, School of Dentistry, Positivo University, Curitiba, PR, Brazil.

\section{Corresponding author:}

Edson Alves de Campos

Rua Professor Pedro Viriato Parigot de Souza,

5300, Campos Comprido

Curitiba - PR - Brazil

CEP: 81280-330

E-mail:edson.campos@up.edu.br

Received for publication on Jul 31, 2008

Accepted for publication on Oct 28, 2008

\begin{abstract}
The purpose of this study was to investigate the influence of chlorhexidine (CHX) concentration on the microtensile bond strength ( $\mu \mathrm{TBS}$ ) of contemporary adhesive systems. Eighty bovine central incisors were used in this study. The facial enamel surface of the crowns was abraded with 600-grit silicon carbide paper to expose flat, mid-coronal dentin surfaces. The tested materials were Scotchbond Multipurpose (SMP), Single-Bond (SB), Clearfil SE Bond (CSEB) and Clearfil Tri S Bond (CTSB). All the materials were applied according to manufacturer's instructions and followed by composite application (Z250). The teeth were randomly divided into 16 groups: for the etch-and-rinse adhesives (SMP and SB), $0.12 \%$ or $2 \%$ CHX was applied prior to or after the acid etching procedure. For the self-etch adhesives (CSEB and CTSB) $0.12 \%$ or $2 \% \mathrm{CHX}$ was applied prior to the primer. Control groups for each one of the adhesive systems were also set up. The specimens were immediately submitted to $\mu$ TBS testing and the data were analyzed using Analysis of Variance and the Tukey post hoc test (alpha $=.01$ ). The failure patterns of the specimens were observed using scanning electron microscopy. The effects of $2 \%$ CHX were statistically significant $(p<0.01)$ for the self-etch adhesives but were not significant for the etch-and-rinse adhesive systems. Analysis of the data demonstrated no statistical difference between the etch-and-rinse adhesive systems. CHX-based cavity disinfectants in concentrations higher than $0.12 \%$ should be avoided prior to the self-etch adhesive systems evaluated in this study to diminish the possibilities of reduction in bond strength.
\end{abstract}

Descriptors: Dentin bonding agents; Chlorhexidine; Bond strength. 


\section{Introduction}

In the past few years, a dramatic improvement in dental adhesive materials and techniques has been observed. While an hermetic seal between several current bonding systems and enamel has been achieved, it is still a big challenge to seal the resindentin interface owing to the heterogeneous character of dentin structure and surface morphology, and/or intrinsic shortcomings in the design of these modern adhesives. ${ }^{1}$

The use of disinfectant solutions is an alternative to reduce or eliminate bacteria from cavity preparations. ${ }^{2}$ To reach this goal, some antibacterial solutions have been evaluated [chlorhexidine (CHX), sodium hypochlorite, fluoride solutions], and the results of different studies are controversial with regard to how the disinfectants affect adhesion. ${ }^{3} \mathrm{CHX}$ has been widely used as an antimicrobial agent, including for disinfection before the placement of restorations. ${ }^{4}$

The purpose of this study was to evaluate the effects of CHX on bond strength using different adhesive systems. The null hypothesis to be tested was that CHX in different concentrations, applied at different stages of the adhesive protocol, does not affect the microtensile bond strength ( $\mu$ TBS) results of the studied etch-and-rinse and self-etch adhesive systems.

\section{Material and Methods}

Eighty bovine central incisors (three years old), extracted and stored in a $0.1 \%$ thymol solution at $5^{\circ} \mathrm{C}$, were used as substitutes for human teeth. The roots were removed with a low-speed diamond saw under water lubrication (Isomet 1000, Buehler Ltd., Lake Bluff, IL, USA), the pulps were removed and the pulp exposure created by cutting the root was sealed with adhesive system and composite (Optibond FL, Kerr Co., Orange, CA, USA; Z250, 3M Espe, MN, USA). Each tooth was then mounted in cold-curing acrylic resin to expose the labial surface.

All the restorative procedures were made under simulated dentinal hydrostatic pressure. A metallic tube was inserted into the pulp chamber of the teeth and sealed with a filled light-cured dentinal adhesive (Optibond FL). This tube was connected by a flex- ible silicon hose to an infusion bottle placed $30 \mathrm{~cm}$ vertically above the test tooth. The infusion bottle was filled with horse serum to simulate the dentinal fluid under normal hydrostatic pressure of about $25 \mathrm{~mm} \mathrm{Hg}$. The pulp chambers were evacuated with a vacuum pump and subsequently filled with the horse serum.

The labial surfaces of the teeth were ground on wet 240 -grit $\mathrm{SiC}$ sandpaper to achieve a flat dentin surface and then polished with 320 and 600-grit $\mathrm{SiC}$ sandpaper under running water to create a standardized smear layer. After ultrasonic cleaning with distilled water for 1 minute to remove any excess debris, the surfaces were washed and dried with oilfree compressed air. Four different adhesive systems were used in this study. For the three-step etch-andrinse adhesive system Adper Scotchbond MultiPurpose - SMP (3M Espe, MN, USA), the dental surface was acid-etched with $37 \%$ phosphoric acid gel for 15 seconds, rinsed for 10 seconds and gently dried with absorbent paper to keep the dentinal surface visibly moist. The primer was applied and dried prior to the application of the adhesive that was light-cured for 10 seconds. A curing unit (Optilux 500, Demetron Research Corp., Danbury, CT, USA) was employed and the $13-\mathrm{mm}$ curing tip was used to cover the entire bonded surface.

The two-step etch-and-rinse adhesive system tested was Adper Single-Bond - SB (3M Espe, MN, USA). Bonding was performed by applying two consecutive coats of self-priming adhesive resin onto the etched dentinal surface $(37 \%$ phosphoric acid gel for 15 seconds), and drying for 5 seconds to evaporate the solvent. The adhesive layer was polymerized for 10 seconds prior to the application of the composite.

The two-step self-etch primer tested was Clearfil SE Bond - CSEB (Kuraray Co., Osaka, Japan). The material was applied with a brush and dried with mild air flow after 20 seconds. The bond liquid was then applied and evenly distributed with a gentle air stream, and light-cured for 10 seconds.

The single-step self-etch adhesive system used was Clearfil Tri S Bond - CTSB (Kuraray Co., Osaka, Japan). The material was applied and dried with air high-pressure after 20 seconds and then lightcured for 10 seconds. 
The teeth were randomly divided into 16 groups: for the etch-and-rinse adhesives (SMP and SB), $0.12 \%$ or $2 \%$ CHX was applied prior to or after the acid etching procedure. For the self-etch adhesives (CSEB and CTSB), $0.12 \%$ or $2 \%$ CHX was applied prior to the primer. Control groups were also set up for each one of the adhesives. Flat 3-mm thick buildups of resin composite (Z250, 3M Espe, MN, USA) were placed in 1-mm increments and each layer was polymerized for 40 seconds. The intra-pulpal pressure was maintained at $25 \mathrm{~mm} \mathrm{Hg}$ during the adhesive procedure and the insertion of composite.

For the microtensile test, the resin-bonded teeth were serially sectioned perpendicular to the adhesive interface into $1-\mathrm{mm}$ thick dentin-resin slices. The slices obtained from the central region of the crown, with approximately $2.0 \mathrm{~mm}$ of dentin thickness, were selected. The reason for that was to standardize the influence of the pulpal hydrostatic pressure. Each slice was trimmed at the bonded interface with a super-fine diamond bur (Komet, Lemgo, Germany) to reduce the bonded surface area to approximately $1.0 \mathrm{~mm}^{2}$. This procedure was always carried out using air-water spray to prevent overheating and cracks. The cross-section surfaces were measured with a digital micrometer (S-T Industries, Inc., Saint James, MN, USA). Both the composite and the dental structure of each specimen were glued with cya-

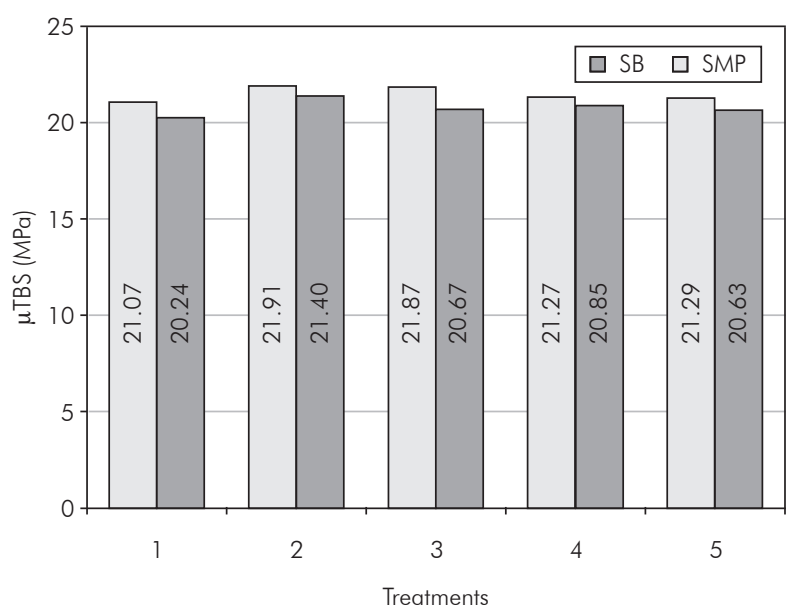

Graph 1 - Mean $\mu$ TBS for the etch-and-rinse adhesives (SMP and SB): 1 - control group; $2-0.12 \% \mathrm{CHX}$ prior to etching; $3-2 \% \mathrm{CHX}$ prior to etching; $4-0.12 \% \mathrm{CHX}$ after etching; 5 - 2\% $\mathrm{CHX}$ after etching. noacrylate adhesive to a modified Bencor Multi-T testing assembly (Danville Engineering, San Ramon, CA, USA) which, in turn, was placed in a universal testing machine (MTS 810, MTS Systems Corporation, Minneapolis, MN, USA) for tensile testing at $1.0 \mathrm{~mm} / \mathrm{min}$. For each condition, a mean bond strength value was calculated from the values obtained with 15 individual slices. Differences among the groups for each material were determined by One-Way Analysis of Variance with Tukey's multiple comparison intervals. The statistical analysis was carried out with the BioEstat software package (version 5.0, IDSM, Tefé, AM, Brazil).

The fractured surfaces were then prepared to observe the fracture pattern. All the specimens were treated with increasing alcohol concentrations up to $100 \%$ alcohol and then left to dry in a desiccator for 12 hours. They were sputter coated with gold and examined under scanning electron microscopy (SEM) (JSM 6400v, JEOL Co., Tokyo, Japan).

\section{Results}

The results were analyzed separately for each adhesive system, since comparisons among materials were not the objective of this work. The results obtained for each adhesive system are shown in Graphs 1 and 2.

The effects of $2 \%$ CHX were statistically signifi-

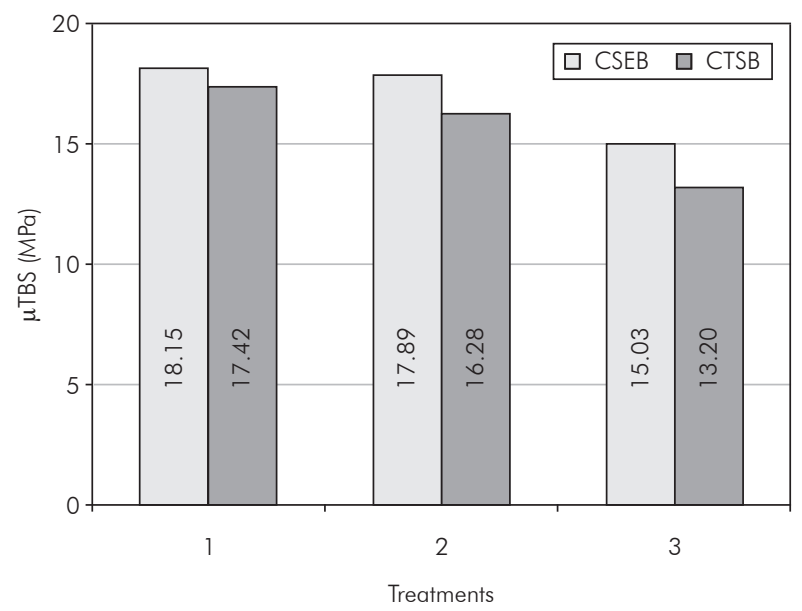

Graph 2 - Mean $\mu$ TBS for self-etch adhesives (CSEB and CTSB): 1 - control group; 2 - 0.12\% CHX prior to the primer; $3-2 \% \mathrm{CHX}$ prior to the primer. 
cant $(\mathrm{p}<0.01)$ for the self-etch adhesives (CSEB and CTSB), but were not significant for the etch-andrinse adhesive systems (SMP and SB). Analysis of the data demonstrated no statistical difference between the three-step and two-step etch-and-rinse adhesive systems (SMP and SB). The means and standard deviations of the $\mu$ TBS tests are summarized in Tables 1 and 2 .

The self-etch adhesive CTSB showed the highest coefficient of variation $(18.13 \%$ for the group treated with $0.12 \% \mathrm{CHX}$ ), and the lowest coefficient of variation was observed with SMP associated to $0.12 \%$ CHX applied prior to the acid etching procedure. The fracture modes were predominantly adhesive, mainly in the specimens restored with self-etch adhesives applied after 2\% CHX (Table 3).

\section{Discussion}

It has been reported that adhesion to the superficial layer of dentin does not differ significantly between human and bovine dentin. ${ }^{5}$ Nakamichi et al. ${ }^{6}$ (1983) have also stated that bovine teeth are useful in the adhesion test as substitutes for human teeth by using enamel and the superficial layer of dentin. Af- ter comparing the number and diameter of dentinal tubules in human and bovine dentine by SEM, Schilke et al. ${ }^{5}$ (1999) concluded that bovine incisor crown dentine is a suitable substitute for human molar dentine in adhesion studies. To reduce the influence of regional variability observed in human dentin and consequently the variations commonly reported with adhesion tests, bovine intermediary dentin was used in this study as a substitute for human dentin. According to Bouillaguet et al..$^{7}$ (2001), bovine dentin has never been considered as a perfect substitute for human dentin in adhesive studies. Anyway, the use of bovine teeth in the present study should have reduced the influence of different levels of permeability commonly observed in human dentin.

Clinicians have used disinfection materials to remove surface contaminants during cavity preparation. It has been postulated that disinfection materials may negatively affect shear bond strength of restorative materials. If so, large numbers of restorations may be predestined for early failure with the use of a disinfection protocol. ${ }^{8}$

Various factors like region of dentin, dentin tubular pattern, presence of smear layer, water content

Table 1 - Means and standard deviations (SD) of $\mu$ TBS (MPa) and coefficient of variation (\%) for the etch-and-rinse adhesives (SMP and SB).

\begin{tabular}{l|c|c|c|c}
\hline \multirow{2}{*}{\multicolumn{1}{c|}{ Group }} & \multicolumn{2}{c|}{ SMP } & \multicolumn{2}{c}{ SB } \\
\cline { 2 - 5 } & Mean $\mu$ TBS (SD) & Coefficient of variation (\%) & Mean $\mu$ TBS (SD) & Coefficient of variation (\%) \\
\hline Control & $21.07(2.25) \mathrm{A}$ & $10.70 \%$ & $20.24(1.24) \mathrm{A}$ & $6.12 \%$ \\
\hline $0.12 \% \mathrm{CHX}$ prior to acid etching & $21.91(1.21) \mathrm{A}$ & $5.52 \%$ & $21.40(1.50) \mathrm{A}$ & $7.03 \%$ \\
\hline $2 \% \mathrm{CHX}$ prior to acid etching & $21.87(1.62) \mathrm{A}$ & $7.40 \%$ & $20.67(1.70) \mathrm{A}$ & $8.21 \%$ \\
\hline $0.12 \% \mathrm{CHX}$ after acid etching & $21.27(1.35) \mathrm{A}$ & $6.34 \%$ & $20.85(1.71) \mathrm{A}$ & $8.21 \%$ \\
\hline $2 \% \mathrm{CHX}$ after acid etching & $21.29(1.82) \mathrm{A}$ & $8.56 \%$ & $20.63(1.49) \mathrm{A}$ & $7.24 \%$ \\
\hline
\end{tabular}

Different capital letters within each column mean statistically significant difference.

Table 2 - Means and standard deviations (SD) of $\mu$ TBS (MPa) and coefficient of variation (\%) for the self-etch adhesives (CSEB and CTSB).

\begin{tabular}{l|c|c|c|c}
\hline \multirow{2}{*}{\multicolumn{1}{c|}{ Group }} & \multicolumn{2}{|c}{ CSEB } & CTSB \\
\cline { 2 - 5 } & Mean $\mu$ TBS (SD) & Coefficient of variation (\%) & Mean $\mu$ TBS (SD) & Coefficient of variation (\%) \\
\hline Control & $18.15(1.78) \mathrm{A}$ & $9.82 \%$ & $17.42(3.09) \mathrm{A}$ & $17.74 \%$ \\
\hline $0.12 \% \mathrm{CHX}$ prior to the primer & $17.89(1.30) \mathrm{A}$ & $7.25 \%$ & $16.28(2.95) \mathrm{A}$ & $18.13 \%$ \\
\hline $2 \% \mathrm{CHX}$ prior to the primer & $15.03(1.74) \mathrm{B}$ & $11.55 \%$ & $13.20(1.90) \mathrm{B}$ & $14.42 \%$ \\
\hline
\end{tabular}

Different capital letters within each column mean statistically significant difference. 


\begin{tabular}{|c|c|c|c|c|c|}
\hline \multirow{17}{*}{$\begin{array}{r}\text { Table } 3 \text { - Type of failure } \\
\text { observed by SEM. }\end{array}$} & Type of failure & Adhesive $^{a}$ & Mixed ${ }^{b}$ & Cohesive $^{c}$ dentin & Composite \\
\hline & SMP - control & 9 & 4 & 1 & 1 \\
\hline & SMP - $0.12 \% \mathrm{CHX}+$ etching & 7 & 5 & 2 & 1 \\
\hline & SMP - $2 \% \mathrm{CHX}+$ etching & 7 & 5 & 3 & - \\
\hline & SMP - etching $+0.12 \% \mathrm{CHX}$ & 10 & 2 & 3 & - \\
\hline & SMP - etching $+2 \% \mathrm{CHX}$ & 10 & 5 & - & - \\
\hline & SB - control & 11 & 2 & 1 & 1 \\
\hline & SB - $0.12 \% \mathrm{CHX}+$ etching & 9 & 5 & 1 & - \\
\hline & $\mathrm{SB}-2 \% \mathrm{CHX}+$ etching & 11 & 2 & 1 & 1 \\
\hline & $\mathrm{SB}-$ etching $+0.12 \% \mathrm{CHX}$ & 9 & 5 & 1 & - \\
\hline & $\mathrm{SB}-$ etching $+2 \% \mathrm{CHX}$ & 8 & 3 & 2 & 2 \\
\hline & CSEB - control & 9 & 2 & 4 & - \\
\hline & CSEB $-0.12 \% \mathrm{CHX}+$ primer & 10 & 4 & - & 1 \\
\hline & CSEB - $2 \% \mathrm{CHX}+$ primer & 13 & 2 & - & - \\
\hline & CTSB - control & 8 & 6 & 1 & - \\
\hline & CTSB $-0.12 \%$ CHX + primer & 7 & 7 & - & 1 \\
\hline & CTSB - $2 \% \mathrm{CHX}+$ primer & 14 & 1 & - & - \\
\hline
\end{tabular}

and erosion/abrasion can influence the tensile bond strength of adhesive systems on dentin. GeraldoMartins et al. ${ }^{3}$ (2007) did not find any influence of $2 \% \mathrm{CHX}$ on marginal microleakage in class $\mathrm{V}$ cavities restored with CSEB, most probably due to the presence of enamel margins. However, this does not mean that all the internal cavity walls were perfectly sealed. In the present study, the adhesion of the selfetch adhesive systems was strongly affected by the application of $2 \% \mathrm{CHX}$. It can be speculated that there are interactions among $\mathrm{CHX}$ and the adhesive components, maybe decreasing their wettability and the level of dentin conditioning. Additionally, the fractured specimens for the self-etch groups showed mainly adhesive failures.

Previous studies have demonstrated that the application of CHX prior to the acid-etching procedure has no adverse effects on immediate composite adhesive bonds in dentin. ${ }^{9-13}$ Even considering that self-etch adhesives are applied on a less permeable surface when compared with etch-and-rinse adhesives due to the presence of smear layer, the adhesion can have been disturbed by the flowing of serum through the dentin. It is known that the adhesive layer acts as a micropermeable layer, ${ }^{14}$ so the outward movement of dentinal fluid under positive pulpal pressure can permeate the adhesive layer and reach the adhesive surface. ${ }^{15}$ Meiers, Kresin ${ }^{2}$ (1996) evaluated the influence of different disinfectants applied prior to the adhesive systems and showed that a CHX-based disinfectant determined higher levels of microleakage, suggesting that the use of cavity disinfectants with composite resin restorations appears to be material specific regarding their interactions with various dentin bonding systems. This opinion is supported by Tulunoglu et al. ${ }^{16}$ (1998), who observed lower bond strength values and higher microleakage associated to $\mathrm{CHX}$.

The results in this study are contrary to the results obtained by Roberts et al. ${ }^{17}$ (2000) that have found a reduction in bond strength using the same two-step etch-and-rinse adhesive (SB) applied after $0.12 \%$ CHX digluconate. Additionally, other authors have demonstrated a negative influence of $2 \%$ CHX on the $\mu \mathrm{TBS}$ of SB in primary teeth. ${ }^{18}$

Another point to be discussed is the interaction of $\mathrm{CHX}$ with the exposed collagen fibrils. Endogenous matrix metalloproteinases (MMPs) are present in crown dentin and their activation results in degradation of hybrid layers created by dentin adhesives. ${ }^{19}$ 
It is speculated that CHX inhibits the dentin MMPs and decelerates the loss of resin-dentin bonds. ${ }^{20}$ This phenomenon would be very interesting in maintaining the long-term durability of dentin-bonds.

\section{Conclusion}

Under the conditions of this study, $0.12 \%$ and $2 \%$ CHX did not show any influence on the immediate $\mu \mathrm{TBS}$ of both etch-and-rinse adhesive systems

\section{References}

1. Yuan Y, Shimada Y, Ichinose S, Tagami J. Qualitative analysis of adhesive interface nanoleakage using FE-SEM/EDS. Dent Mater. 2007 May;23(5):561-9.

2. Meiers JC, Kresin JC. Cavity disinfectants and dentin bonding. Oper Dent. 1996 Jul-Aug;21(4):153-9.

3. Geraldo-Martins VR, Robles FR, Matos AB. Chlorhexidine's effect on sealing ability of composite restorations following Er:YAG laser cavity preparation. J Contemp Dent Pract. 2007 Jul;8(5):26-33.

4. Carrilho MR, Carvalho RM, de Goes MF, di Hipolito V, Geraldeli S, Tay FR et al. Chlorhexidine preserves dentin bond in vitro. J Dent Res. 2007 Jan;86(1):90-4.

5. Schilke R, Bauss O, Lisson JA, Schuckar M, Geurtsen W. Bovine dentin as a substitute for human dentin in shear bond strength measurements. Am J Dent. 1999 Apr;12(2):92-6.

6. Nakamichi I, Iwaku M, Fusayama T. Bovine teeth as possible substitutes in the adhesion test. J Dent Res. 1983 Oct; 62(10):1076-81.

7. Bouillaguet S, Gysi P, Wataha JC, Ciucchi B, Cattani M, Godin $\mathrm{C}$ et al. Bond strength of composite to dentin using conventional, one-step, and self-etching adhesive systems. J Dent. 2001 Jan;29(1):55-61.

8. Pappas M, Burns DR, Moon PC, Coffey JP. Influence of a 3 -step tooth disinfection procedure on dentin bond strength. J Prosthet Dent. 2005 Jun;93(6):545-50.

9. Perdigao J, Denehy GE, Swift Jr EJ. Effects of chlorhexidine on dentin surfaces and shear bond strengths. Am J Dent. 1994 Apr;7(2):81-4.

10. de Castro FL, de Andrade MF, Duarte Junior SL, Vaz LG, Ahid FJ. Effect of $2 \%$ chlorhexidine on microtensile bond strength of composite to dentin. J Adhes Dent. 2003 Summer;5(2):129-38. tested. However, the application of $2 \% \mathrm{CHX}$ was deleterious to self-etch adhesive systems. At this time, CHX-based cavity disinfectants in concentrations higher than $0.12 \%$ should be avoided prior to the self-etch adhesive systems evaluated in the present study to diminish the possibilities of reduction in bond strength. Further studies are necessary to improve the understanding about interactions between disinfectant solutions and adhesive components.

11. Soares CJ, Pereira CA, Pereira JC, Santana FR, do Prado CJ. Effect of chlorhexidine application on microtensile bond strength to dentin. Oper Dent. 2008 Mar-Apr;33(2):183-8.

12. Santos JN, Carrilho MR, De Goes MF, Zaia AA, Gomes BP, Souza-Filho FJ et al. Effect of chemical irrigants on the bond strength of a self-etching adhesive to pulp chamber dentin. J Endod. 2006 Nov;32(11):1088-90.

13. Turkun M, Turkun LS, Kalender A. Effect of cavity disinfectants on the sealing ability of nonrinsing dentin-bonding resins. Quintessence Int. 2004 Jun;35(6):469-76.

14. Chersoni S, Suppa P, Breschi L, Ferrari M, Tay FR, Pashley $\mathrm{DH}$ et al. Water movement in the hybrid layer after different dentin treatments. Dent Mater. 2004 Nov;20(9):796-803.

15. Tay FR, Frankenberger R, Krejci I, Bouillaguet S, Pashley DH, Carvalho RM et al. Single-bottle adhesives behave as permeable membranes after polymerization. I. In vivo evidence. J Dent. 2004 Nov;32(8):611-21.

16. Tulunoglu O, Ayhan H, Olmez A, Bodur H. The effect of cavity disinfectants on microleakage in dentin bonding systems. J Clin Pediatr Dent. 1998 Summer;22(4):299-305.

17. Roberts HW, Karpay RI, Mills SE. Dental unit waterline antimicrobial agents' effect on dentin bond strength. J Am Dent Assoc. 2000 Feb;131(2):179-83.

18. Vieira R de S, da Silva Jr IA. Bond strength to primary tooth dentin following disinfection with a chlorhexidine solution: an in vitro study. Pediatr Dent. 2003 Jan-Feb;25(1):49-52.

19. Tay FR, Pashley DH, Loushine RJ, Weller RN, Monticelli F, Osorio R. Self-etching adhesives increase collagenolytic activity in radicular dentin. J Endod. 2006 Sep;32(9):862-8.

20. Gendron R, Grenier D, Sorsa T, Mayrand D. Inhibition of the activities of matrix metalloproteinases 2, 8, and 9 by chlorhexidine. Clin Diagn Lab Immunol. 1999 May;6(3):437-9. 